Revista de la red interuniversitaria de estudios sobre las literaturas rioplatenses contemporáneas en Francia

16 | 2017

Esnobismos

\title{
La desintegración del esnob : la fotografía en la obra de Charles Baudelaire y Lucio V. Mansilla
}

\section{Mariana de Cabo}

\section{OpenEdition}

\section{Journals}

Electronic version

URL: http://journals.openedition.org/lirico/3391

DOI: $10.4000 /$ lirico.3391

ISSN: 2262-8339

\section{Publisher}

Réseau interuniversitaire d'étude des littératures contemporaines du Río de la Plata

\section{Electronic reference}

Mariana de Cabo, «La desintegración del esnob : la fotografía en la obra de Charles Baudelaire y Lucio V. Mansilla », Cuadernos LIRICO [En línea], 16 | 2017, Puesto en línea el 16 septiembre 2017, consultado el 19 abril 2019. URL : http://journals.openedition.org/lirico/3391 ; DOI : 10.4000/lirico.3391

This text was automatically generated on 19 April 2019.

\section{(c) (†) $\odot$}

Cuadernos LIRICO está distribuido bajo una Licencia Creative Commons Atribución-NoComercialSinDerivar 4.0 Internacional. 


\title{
La desintegración del esnob : la fotografía en la obra de Charles Baudelaire y Lucio V. Mansilla
}

\author{
Mariana de Cabo
}

1 La escritura fragmentaria de Lucio V. Mansilla encuentra su público a fines del siglo XX. A lo largo del breve prólogo a Esa cabeza toba y otros textos (2001) de Mansilla, César Aira elogia el impulso desintegrador del escritor decimonónico :

\begin{abstract}
Al parecer Mansilla vivió con el temor de disgregarse. No salía a caminar de noche por miedo a los perros sueltos, que lo estaban esperando para separarle brazos y piernas a dentelladas. Acariciaba el curioso terror de perder los dedos uno a uno. Si se quedaba diez minutos solo, veía flotando en el aire una cabeza de indio. La digresión, agazapada como una bestia ya en su decisión de ponerse a hablar, era implacable en el descalabramiento del discurso; y como su única defensa contra la disgregación era ponerse a hablar, y seguir hablando, tuvo que hacer de necesidad virtud, y el cambio de tema fue su estilo y su elegancia.
\end{abstract}

En la causerie «Alucinación», Mansilla (1963: 40) reconoce abiertamente su locura y confiesa haber visto fantasmas y haber adoptado diferentes personalidades. ¿Cómo explicar su procedimiento literario ? ¿Cómo logra el autor asumir otros "yos” sin perder la integridad de su persona? La lectura del esnob victorioso, el escritor independiente, que realiza Víctor Goldgel (2014) nos permitirá comprender el surgimiento de Mansilla en un campo intelectual donde los escritores todavía no pueden ejercer su profesión de forma autónoma. Pues cuando Mansilla se pierde en extensas digresiones y alcanza el vacío, logra posicionarse como escritor de ficción en un mercado donde la literatura todavía debe responder a los intereses políticos y económicos de su tiempo. Es así que frente al autor argentino de la generación del 80, cuya autonomía se considera impensable (Jitrik, 1968), Mansilla se erige en el « primer escritor (argentino) de ficción » (Contreras, 2014), un escritor más próximo al siglo XX tardío que a los tiempos anteriores que no supieron comprenderlo'

3 La escritura de Mansilla se ubica en el curso cronológico de los escritores dandies, esnobs victoriosos, que se caracterizan por cuestionar la integridad del yo y la finalidad de la 
escritura. Mansilla sigue, en especial, a Baudelaire, el modelo clásico de dandi, en su impulso por adoptar otros yos, por pasar por lo que no es. Baudelaire instruye con su ejemplo al argentino: mientras Baudelaire pasa por homosexual en Bélgica, Mansilla simula ser el general Cialdini en Roma (Molloy, 1980). Así lo confiesa de manera velada Mansilla (1966 : 392) en « Un hombre comido por las moscas » : el narrador afirma que no padece de « un dandismo satánico » igual que Baudelaire, ya que no se viste «à la diable » ni habla como un antropófago. Pero, como observa Julio Schvartzman (1996: 154), su vestimenta es insurrecta y su obra juega con el tópico del caníbal en el capítulo 46 de Una Excursión a los indios ranqueles y en la causerie "¿Por qué...? ?. En este marco de análisis, nuestro trabajo busca analizar cómo Baudelaire y Mansilla, en su calidad de esnobs victoriosos, pierden su yo a través de la escritura y de la fotografía.

¿Pero en qué consiste el esnob victorioso ? Según explica Goldgel (2014 : 243), a diferencia del esnob fracasado, es decir el rastacuero, que padece las diferencias entre clase alta y baja, entre centro cultural parisino y periferia de América Latina, el esnob victorioso latinoamericano se desentiende de las jerarquías sociales para buscar lo nuevo y lo exótico. Baudelaire $(1975, \mathrm{I}, 134)$ lo anuncia en « Le voyage » : « Au fond de l'inconnu pour trouver du nouveau »; Mansilla (1984: 7-8) lo confiesa al concluir que la curiosidad lo condujo a la tierra de los ranqueles :

Hacía ya mucho tiempo que yo rumiaba el pensamiento de ir a Tierra Adentro.

El trato con los indios que iban y venían al Río Cuarto, con motivo de las negociaciones de paz entabladas, había despertado en mí una indecible curiosidad.

Es menester haber pasado por ciertas cosas, haberse hallado en ciertas posiciones, para comprender con qué vigor se apoderan ciertas ideas de ciertos hombres; para comprender que una misión a los ranqueles puede llegar a ser para un hombre como yo, medianamente civilizado, un deseo tan vehemente, como puede ser para cualquier ministeril una secretaría en la embajada de París.

5 La voluntad de conocer se apropia del esnob victorioso, lo angustia y lo conduce hacia los extremos: «Tu connais cette maladie fiévreuse qui s'empare de nous dans les froides misères, cette nostalgie du pays qu'on ignore, cette angoisse de la curiosité ?» (Baudelaire, 1975 : 302). El deseo de experimentar mil formas dirige a estos sujetos que se entregan por entero al goce estético :

Digan lo que quieran, si la felicidad existe, si la podemos concretar y definir, ella está en los extremos. Yo comprendo las satisfacciones del rico y las del pobre ; las satisfacciones del amor y del odio; las satisfacciones de la oscuridad y las de la gloria. Pero ¿quién comprende las satisfacciones de los términos medios; las satisfacciones de la indiferencia ; las satisfacciones de ser cualquier cosa? (Mansilla, $1984: 5)$.

Para responder a este ansía se desentienden de las reglas de la sociedad y adoptan diferentes apariencias sin fijar una sola (Goldgel, 2014 : 246). Es así que Mansilla (1975 : 51) critica contantemente la dicotomía civilización-barbarie :

Te asombrarías, si volvieses a estas tierras lejanas y vieras lo que hemos adelantado. Buscarías inútilmente el molino del viento; el pino de la quinta de Guido se ha escapado por milagro. La civilización y la libertad han arrasado todo.

El Paraguay no existe. La última estadística después de la guerra arroja la cifra de ciento cuarenta mil mujeres y catorce mil hombres.

7 En la misma línea, Baudelaire repudia el progreso material y no moral de la civilización. La única mejora posible se dará en el orden moral porque, según afirma el poeta en Fusées, el hombre "[...] est toujours semblable et égal à l'homme, c'est-à-dire toujours à l'état sauvage !” (1975 : 663). Es decir que, de acuerdo con Baudelaire (1975 : 697), el esplendor 
de la civilización no se encuentra ni en el gas, ni el vapor, sino en "[...] la diminution des traces du péché originel".

Por medio de la teatralidad, ambos escritores objetan la autenticidad de las formas del mundo y coronan la primacía del arte por el arte : la fotografía y la escritura constituyen sus medios de expresión. Este comportamiento se convierte en un signo del esnob triunfante, el dandi, que adopta diferentes apariencias y desintegra su yo para desentenderse de los límites de la sociedad de su tiempo.

\section{El retrato del escritor en la era fotográfica de la literatura}

9 Desde su nacimiento, la fotografía se presenta como una invención polémica, ya que ni sus creadores ni el público que le es contemporáneo pueden comprenderla. Según Michel Frizot (1989: 6), a diferencia de otras invenciones, los efectos y usos de la fotografía resultan imprevisibles, pues ni siquiera los inventores saben precisamente qué buscan ni el valor de sus hallazgos. En este contexto polémico, Baudelaire y Mansilla conocen la fotografía: cuando en 1826 Baudelaire cumple cinco años, Niépce toma la primera fotografía de la historia, « Point de vue du Gras »; en 1839, al alcanzar los dieciocho años, el poeta descubre la difusión pública del daguerrotipo en París. Mansilla, por su parte, tiene nueve años cuando en 1840 los exiliados del gobierno de Rosas conocen y documentan el daguerrotipo en Uruguay. Es más, al construir su figura de autor Mansilla se vale, como Baudelaire, de la fotografía ${ }^{2}$. De esta manera, ambos (autores) usan el espacio de la fotografía para que el yo adopte diferentes formas y transforman ese espacio en espacio ficcional, como su obra.

10 En el contexto general del siglo XIX donde, como señala Molloy (2012: 43), «[...] las culturas se leen como cuerpos [...]", se ubica la preocupación por la imagen de autor. Nos encontramos frente a la era fotográfica de la lectura de los cuerpos como libros, donde un esnob como Baudelaire y Mansilla hace de sí mismo una obra artística. Según Molloy (2012: 43), el poseur trabaja a través de la corporeidad, los gestos, «[...] su inevitable proyección teatral, sus connotaciones plásticas [...]» para crear la pose. Es sí que en « Horror al vacío » Mansilla posa y se convierte en la versión francesa de Lucio :

-Monsieur, je n'ai pas l'honneur de vous connaître.

Ficción... lo conocía perfectamente : era un prójimo de acá de Buenos Aires, que Dios sabe qué viento lo había llevado al otro hemisferio; que yo conocía desde que él comenzó a decir ajó ; que en su vida me había saludado ; que jamás había tenido conmigo la más mínima cortesía, y que nada más que porque estábamos en el extranjero, ya se imaginaba que debíamos de tratarnos de tú y vos (1963 : 324).

11 En el tiempo de Baudelaire y Mansilla, la imagen se vuelve una obsesión: el aspecto exterior y su exhibición adquieren gran importancia. Molloy sintetiza de esta manera el auge de la imagen en el siglo XIX :

La exhibición, como forma cultural, es el género preferido del siglo XIX, la escopofilia, la pasión que la anima. Todo apela a la vista y todo se especulariza : se exhiben nacionalidades en las exposiciones universales, se exhiben nacionalismos en los grandes desfiles militares (cuando no en las guerras mismas concebidas como espectáculos), se exhiben enfermedades en los grandes hospitales, se exhibe el arte en los museos, se exhibe el sexo artístico en los « cuadros vivos» o tableaux vivants, se exhiben mercaderías en los grandes almacenes, se exhiben vestidos en los salones de modas, se exhiben tanto lo cotidiano como lo exótico en fotografías, 
dioramas, panoramas. Hay exhibición y también hay exhibicionismo. La clasificación de la patología (« obsesión morbosa que lleva a ciertos sujetos a exhibir sus órganos genitales ") data de 1866; la creación de la categoría individual, exhibicionista -categoría que marca el paso del acto al individuo -, de 1880 (Molloy, 2012: 43).

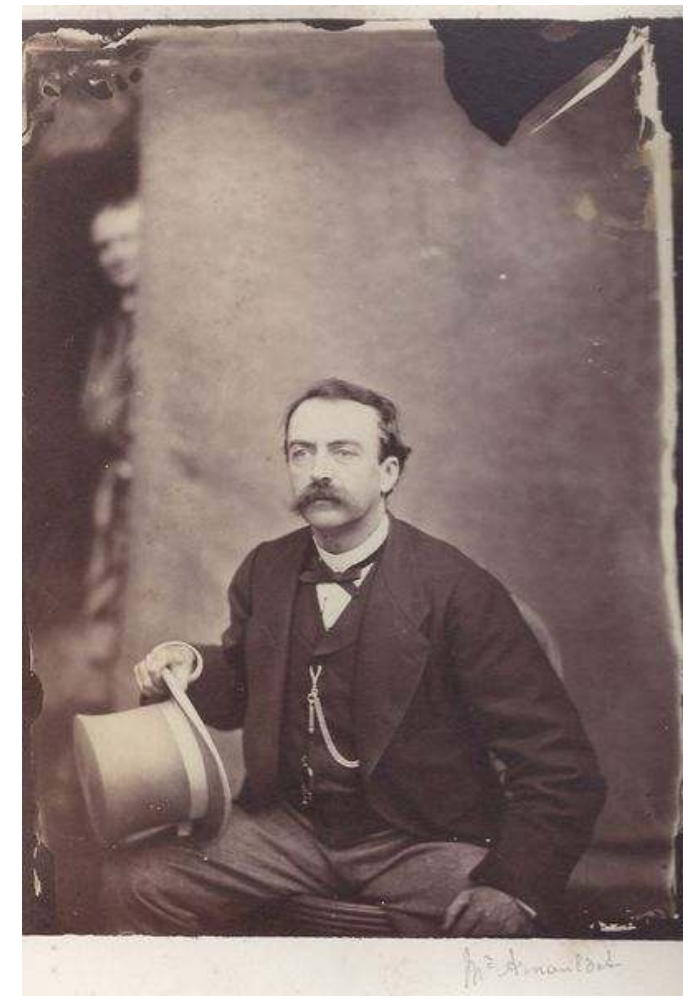

Fiura 1

«Un air de Baudelaire»

Étienne Carjat, 1861, Musée d'Orsay 


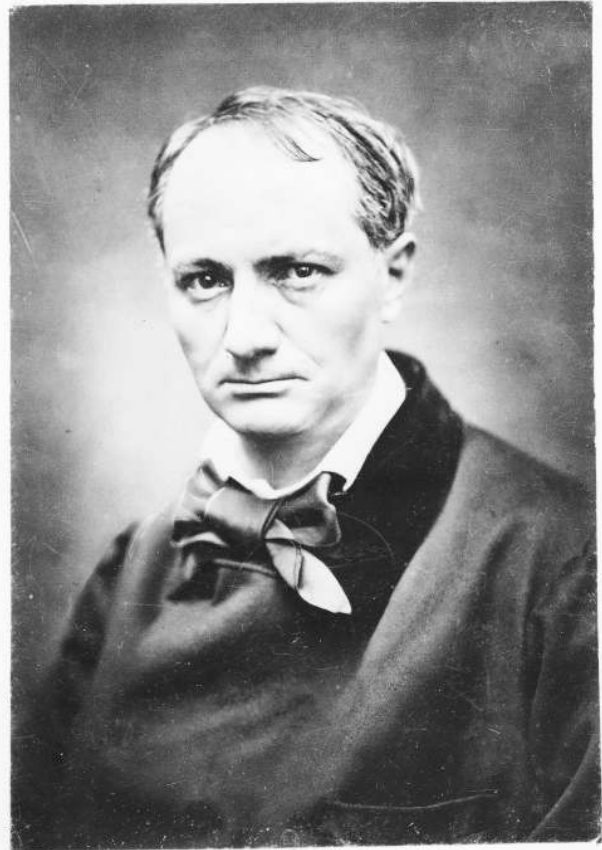

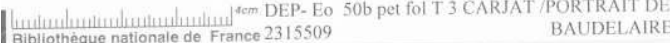

Figura 2

"Portrait de Charles Baudelaire »

Étienne Carjat, s/f, BNF

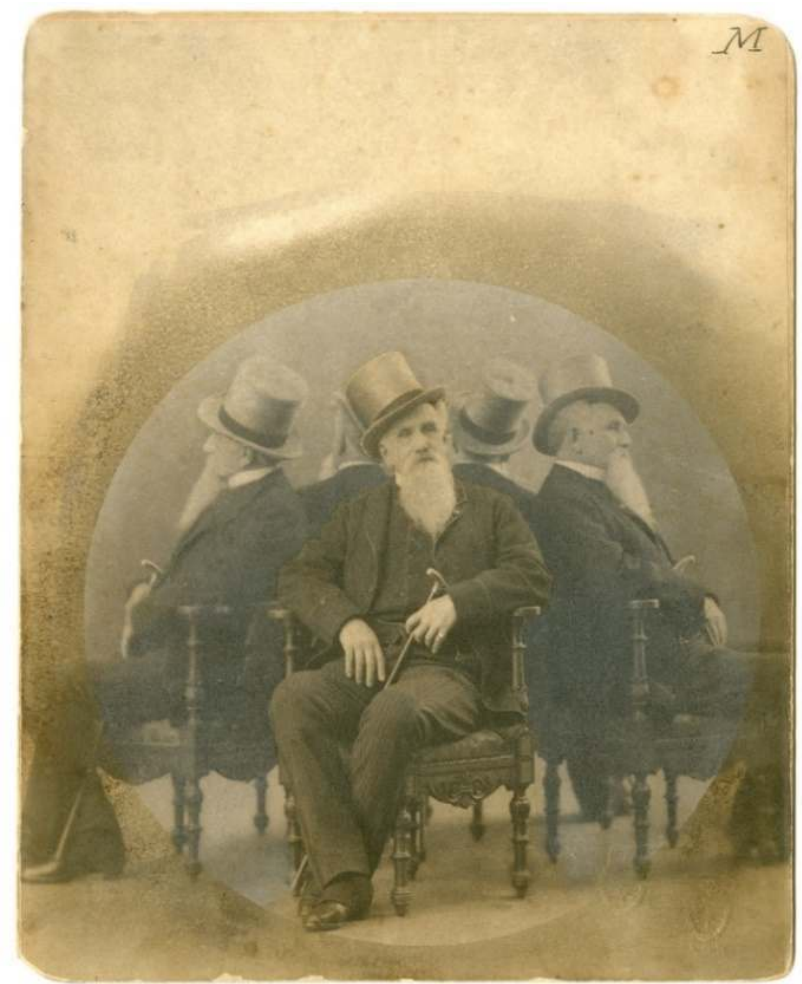

Figura 3

"Mansilla siendo general »

Alejandro Witcomb, 1903, Archivo general de La Nación 

posar, es decir, actuar, transformarse, ser otros. La figura 1 presenta una puesta en escena insólita para la época: Baudelaire irrumpe inesperadamente durante el acto fotográfico. Al parecer el mismo día que Étienne Carjat toma la famosa fotografía de Baudelaire (figura 2), posa Thomas Arnauldet en el atelier del fotógrafo en la rue Laffitte y se registra detrás del telón la silueta del poeta. Serge Plantureux, el comerciante que obtiene la fotografía, explica a Jérôme Dupuis (2013 : en línea) del diario L'Express la historia de la desconocida fotografía. Fascinado por la imagen fantasmal detrás de escena, Plantureux compra el positivo por pocos euros a un desconocido y al final logra venderlo al Musée d'Orsay por 50.000 euros. Se trata de una copia de papel albuminado tomada a partir de un negativo de vidrio de colodión. Sobre la fotografía está escrito el nombre « $\mathrm{Mr}$ Arnauldet ». De acuerdo con Plantureux, si bien el señor Arnauldet no figura en la correspondencia de Baudelaire, Jean Andhémar, bibliotecario de la BNF y uno de los organizadores de la exposición sobre el centenario de Les Fleurs du Mal en 1957, explica que Arnauldet fue bibliotecario del gabinete de estampas de la BNF entre 1858 y 1869 y amigo de Baudelaire (Dupuis, 2013 : en línea). La fotografía se adjudica a Carjat porque el aspecto del desconocido y su atuendo coinciden con el de la célebre toma de Baudelaire. Plantureux efectúa una profunda investigación que le permite descubrir ciertos datos sobre Mr Arnauldet. Al parecer Thomas Arnauldet nació en 1834 y pertenecía a una familia muy prestigiosa y rica de Poitou. Además, compartía con Baudelaire su afición por el grabado y, especialmente, la caricatura.

Como puntualiza François Soulages (2005: 80-82), la fotografía teatraliza la realidad: cuando observamos los retratos de los escritores, no reconocemos una prueba de lo real, sino el indicio de una simulación, la actuación de un personaje. Se trata de la puesta en escena fundadora del mito del poète de la bohème en el caso de Baudelaire, y del mito del « mestizo peculiar» (Viñas, 2009) o del « ciudadano de la frontera » (Iglesia, 2003: 94) en el caso de Mansilla. Pues así como Baudelaire forma el Panthéon Nadar, Mansilla, según Viñas (1964 : 207), desea alcanzar «el panteón de los héroes nacionales». Tanto en sus escritos como en sus fotografías el escritor esnob juega entre la ficción y la realidad: mezcla la literatura con la vida. Para Baudelaire y Mansilla no importa revelar su yo, sino ocultarse a través de máscaras, ambigüedades y apariencias : ocultarse tras su obra y tras el reflejo de su imagen.

El análisis de la simulación en las fotografías de los escritores remite a la ancestral idea del doble representada, según explica Jacques Aumont (1992: 15), en los símbolos del espejo y de la sombra. Se trata del doble literario de Baudelaire y Mansilla, la creación que los escritores hacen de sí mismos. La presencia de la sombra atraviesa los retratos de Baudelaire y Mansilla en los juegos de luz y se propaga por su escritura opacada por la bruma y la luz crepuscular. La alegoría del espejo, el otro reflejado, según analizaremos, recorrerá la obra de ambos escritores. Por otro lado, cuando nos referimos al doble, aludimos al rostro, creador de la analogía humana. De acuerdo con Aumont (1992: 15), el rostro, al ser la única parte que no podemos ver de nosotros mismos, se ubica entre el polo de lo visible y de lo invisible, de la mirada interior y de los misterios que encierra la multiplicidad de facetas que esconde el poseur. En la mayoría de los retratos de Baudelaire y Mansilla, el rostro se dirige a la cámara : este gesto, según explica Soulages (2005: 52) al parafrasear a Braisson, denuncia la fábula, la actuación del doble y de la imprecisa copia de la realidad, la simulación del otro yo. Por eso en La Fanfarlo, cuando Samuel Cramer observa el reflejo de su rostro en el espejo, llora : « Une larme lui germait-elle dans le coin 
de l'oeil à quelque souvenir, il allait à sa glace se regarder pleurer " (Baudelaire, 1975-1976, vol. I : 554).

15 Al aludir a las infinitas poses de los escritores frente a la cámara, no olvidemos el valor mágico y siniestro que adquieren los diferentes yos fijados en el positivo de la fotografía. Es así que en 1839, cuando Arago presenta en sociedad el primer daguerrotipo, no sólo revoluciona la ciencia, sino que también logra agitar las aparentemente tranquilas aguas del arte y de los códigos de representación : la creación de un medio icónico espanta al público. En este sentido, Nadar describe hasta qué punto la fotografía moviliza al siglo XIX :

Mais tant de prodiges nouveaux n'ont-ils pas à s'effacer devant le plus surprenant, le plus troublant de tous: celui qui semble donner enfin à l'homme le pouvoir de créer, lui aussi, à son tour, en matérialisant le spectre impalpable qui s'évanouit aussitôt aperçu sans laisser une ombre au cristal du miroir ; un frisson à l'eau du bassin? L'homme ne put-il croire qu'il créait en effet lorsqu'il saisit, appréhenda, figea l'intangible, gardant la vision fugace, l'éclair, par lui gravés aujourd'hui sur l'airain le plus dur? (1895-1905: 4).

16 Sin duda, la posibilidad de asir el espectro humano o, como sostiene Cortés-Rocca (2011: 42), de conservar una « huella de lo real » se consideraba inconcebible hasta el arribo de la fotografía. Antes, la representación constituía un signo arbitrario de la realidad, pero con la nueva técnica la imagen se convierte, más que en un testimonio directo del mundo reproducido, en « [...] una 'porción de realidad robada al mundo`» (Cortés-Rocca, 2011: 42). La fotografía siempre deberá reproducir su referente, jamás podrá dejar de mostrar aquello a lo que alude : en esto, se ve condenada o bendecida por su condición tautológica (Barthes, 2011 : 30). A esta unión de la fotografía con su objeto, Barthes (2011: 31) la relaciona con el tiempo fijo de la técnica, dado que, en el mundo de las contingencias y de lo pasajero, la disciplina se une eternamente a su referente. Incluso en nuestros días el peso de la iconicidad fotográfica no ha dejado de dominar la fotografía y captar toda la atención del público, lo que lleva a Barthes a escribir :

¿Qué me importaban a mí las reglas de composición del paisaje fotográfico o, en el otro extremo, la Fotografía como rito familiar? Cada vez que leía algo sobre la Fotografía pensaba en tal o cual foto preferida, y ello me encolerizaba. Pues yo no veía más que el referente, el objeto deseado, el cuerpo querido; pero una voz importuna (la voz de la ciencia) me decía entonces con tono severo: "Vuelve a la Fotografía. Lo que ves ahí y que te hace sufrir está comprendido en la categoría de "Fotografías de aficionados », sobre la que ha tratado un equipo de sociólogos : no es más que la huella de un protocolo social de integración destinado a sacar a flote a la Familia, etcétera". Sin embargo, yo persistía; otra voz, la más fuerte, me impulsaba a negar el comentario sociológico ; frente a ciertas fotos yo deseaba ser salvaje, inculto (2011:32-33).

Si Barthes en la edad contemporánea considera hipnótica la condición icónica de la fotografía, imaginemos el grado de misterio e incógnita que genera en 1839 la nueva invención. Balzac, aterrorizado, piensa en las implicancias metafísicas de la fotografía y formula la teoría de los espectros. Según el escritor, señala Nadar (1895-1905: 6), todo cuerpo se encuentra formado por un número de espectros que son destruidos por cada disparo de la cámara. Es así que el daguerrotipo prueba la existencia de lo inmaterial al asir el aura invisible de cada persona. Un proceso que atemoriza no sólo a Balzac, sino también a sus seguidores : a Nerval y a Gautier y, por supuesto, a Baudelaire y a Mansilla. En « De cómo el hambre me hizo escritor », Mansilla recrea el extrañamiento que produce ese otro yo que lo observa: «Me paseaba agitado por el cuarto : iba, venía; en una de 
esas, me detuve, me miré al espejo turbio, que era todo el ajuar de tocador que allí había, y mi cara me pareció grotesca » (Mansilla, 1963 : 108).

La rigurosa réplica de un otro tan similar al modelo original nos remonta al eterno miedo que genera la imagen a lo largo del tiempo. Con la fotografía, se inaugura un nuevo paganismo, el culto a la imagen que resucita conceptos ancestrales de las primeras religiones politeístas. Por eso no nos extraña el tinte divino que Baudelaire (1976, II, 617) otorga a la polémica cuando describe en el Salon de 1859 a la técnica como una idolatría y a Daguerre como su « Messie ».

19 Además, el referente fotográfico también facilita el surgimiento del doble. Barthes describe el fenómeno de una manera muy ilustrativa : «[...] percibo el referente (aquí la fotografía se sobrepasa realmente a sí misma : ¿no es acaso la única prueba de su arte? ¿Anularse como 'médium', no ser ya un signo, sino la cosa misma ?) [...] » (Barthes, 2011 : 83). Es decir que, gracias al grado de precisión de la fotografía, el retratado cobra vida y se convierte en un otro, similar al modelo, pero inmóvil en el tiempo y adorado por el orgulloso burgués que se embelesa como Narciso ante su propio reflejo. A su vez, al describir la huella fotográfica, Barthes impele al lector a tomar conciencia de la revolucionaria forma de verse a uno mismo que instaura la técnica :

[...] la Fotografía es el advenimiento de yo mismo como otro, una disociación ladina de la conciencia de identidad. Algo aún más curioso: es antes de la Fotografía cuando los hombres hablaron más de la visión del doble. Se compara la heautoscopia a una alucinosis; durante siglos fue un gran tema mítico. Pero hoy ocurre como si desechásemos la locura profunda de la Fotografía : ésta sólo nos recuerda su herencia mítica por el ligero malestar que me embarga cuando «me » miro en un papel (2011: 40).

Por otra parte, si bien se encuentra latente el peligro del artista prometeico a causa del grado de referencialidad de la imagen fotográfica, la divinidad del fotógrafo pasa a un segundo plano : sólo se ve al retratado, el fotógrafo se ve opacado (Cortés-Rocca, 2011 : 51) y no se sabe si la imagen pertenece al fotografiado o al fotógrafo (Barthes, $2011: 41$ ). Es decir que la divinización del modelo burgués se acrecienta aún más. Asimismo, la preponderancia del carácter indicial de la imagen trastoca los tradicionales valores del retrato. En la modernidad, el rostro ya no representa un reflejo del alma, dado que las apariencias se tornan engañosas, lo oculto se insinúa a través de lo visible (Cortés-Rocca, 2011: 43) o se esconde al individuo bajo la máscara del estereotipo social burgués (Aumont, 1992: 22). Por eso, al analizar las fotografías de Baudelaire y de Mansilla, intentamos develar la verdad que esconden los gestos del esnob victorioso y qué motiva la afición por la propia imagen. El poeta describe la situación de la siguiente manera : «Le dandy doit aspirer à être sublime, sans interruption. Il doit vivre et dormir devant un miroir » (Baudelaire, 1975, I, 678). Este miroir simula a la cámara : el aparato que fija el reflejo del hombre en el papel para reproducirlo al infinito y desintegrarlo.

\section{Extrema exposición del individuo}

En el siglo XIX, se propaga un credo narcisista cuyos fieles se convierten en potenciales dioses. La fotografía genera esta situación al facilitar, con la multiplicación del rostro de cada individuo, el culto a la propia imagen. A través del espejo de la cámara se concibe una alegoría que despersonifica la unidad del autor (Starobinski, 1989: 35) : el yo del esnob al adoptar las diversas formas que refleja se desintegra. Baudelaire (1975, I, 678) 
plasma este concepto en El pintor de la vida moderna cuando Guys se transforma en espejo, es decir, en múltiples otros : " On peut aussi le comparer, lui, à un miroir aussi immense que cette foule [...] ». La imagen del artista entre la muchedumbre capta a la perfección la forma de la cámara fotográfica: un dispositivo que trabaja con diferentes lentes que reflejan. De la misma manera, en « Les Foules » de Le Spleen de Paris, se elogia el arte de ser otro, la « singulière ivresse de cette universelle communion » :

Il n'est pas donné à chacun de prendre un bain de multitude : jouir de la foule est un art ; et celui-là seul peut faire, aux dépens du genre humain, une ribote de vitalité, à qui une fée a insufflé dans son berceau le goût du travestissement et du masque, la haine du domicile et la passion du voyage (Baudelaire, 1975, I, 291).

Incluimos también la parte en la que el yo poético alaba la posibilidad del poeta de transformarse en otro :

Le poète jouit de cet incomparable privilège, qu'il peut à sa guise être lui-même et autrui. Comme ces âmes errantes qui cherchent un corps, il entre, quand il veut, dans le personnage de chacun. Pour lui seul, tout est vacant; et si de certaines places paraissent lui êtres fermées, c'est qu'à ses yeux elles ne valent pas la peine d'être visitées.

[...] Il adopte comme siennes toutes les professions, toutes les joies et toutes les misères que la circonstance lui présente.

Ce que les hommes nomment amour est bien petit, bien restreint et bien faible, comparé à cette ineffable orgie, à cette sainte prostitution de l'âme qui se donne tout entière, poésie et charité, à l'imprévu qui se montre, à l'inconnu qui passe (Baudelaire, 1975, I, 291).

En « Les Tentations ou Éros, Plutus et la Gloire » uno de los dones que ofrece « la Gloire », el primero de los diablillos, al yo poético consiste en el éxtasis de poder adoptar otras formas y de perder los límites de la propia al unirse con los otros :

« Si tu veux, si tu veux, je te ferai le seigneur des âmes, et tu seras le maitre de la matière vivante, plus encore que le sculpteur peut l'être de l'argile ; et tu connaîtras le plaisir, sans cesse renaissant, de sortir de toi-même pour t'oublier dans autrui, et d'attirer les autres âmes jusqu'à les confondre avec la tienne. » (Baudelaire, 1975, I, 308).

¿No podría acaso interpretarse este fragmento como una velada descripción del proceso fotográfico que permite al fotógrafo consustanciarse con las diversas formas que capta? ¿Acaso el esnob victorioso no persigue el mismo fin al simular diferentes formas? Mansilla, por su parte, logra la desintegración especular en la fotografía trucada de Witcomb de 1903 (ver figura 3). Según Abel Alexander, historiador de la fotografía, para realizar el famoso truco de los espejos, el modelo debe ubicarse entre la cámara y dos espejos enfrentados entre sí. De esta manera, los espejos reproducen el reflejo del modelo y el reflejo del reflejo: el poseur logra multiplicarse hasta cinco veces. En el caso de "Catherine Necrassoff», Mansilla multiplica el objeto deseado, una dama en el tren, para poseerlo :

Cuando se viaja no hay contacto, por más que uno se toque, y al rato, todos estábamos a gusto, al menos yo lo estaba, porque mi vecina, cuya cara, llena de seducción, podía ver perfectamente, sin mirarla, por el espejo de enfrente, que la repercutía, era toda una cumplida vecina [...] (Mansilla, $1963: 176)$. general Mansilla y Lucio Victorio :

Bien resulta de lo que dejo dicho, que hay noches en las que Lucio Victorio está contento del general ; otras, en las que el general está contento de Lucio Victorio, y viceversa, noches en las que el general suele decirle a Lucio Victorio : ¡pero hombre, 
qué bárbaro has estado hoy, qué indiscreto, qué imprudente !; noches en las que Lucio Victorio suele decirle al general : pero amigo, qué mal sentido el suyo; y noches en las que los dos se acuestan cuasi contentos, no recordando haber hecho ninguna zoncera (Mansilla, 1963 : 490-491).

Entre la pluma y la espada, se confrontan los dos yos de un escritor que fracasó en el plano político para alcanzar la victoria en el campo intelectual. Hubo que esperar hasta fines del siglo XX para que su obra encontrará en la era posmoderna al lector de sus digresiones. En este sentido, Goldgel (2014 : 247) elogia la simulación de Mansilla :

Lo interesante, sin embargo, es que en ciertos contextos la simulación puede efectivamente ser concebida como una forma de acceso a lo auténtico: lo que diferencia a un dandi como Lucio V. Mansilla del ridículo catrín, por ejemplo, no es tanto su pertenencia a la oligarquía o su mayor capital simbólico como el hecho de que el mundo en el que se mueve admite la posibilidad de una simulación victoriosa.

Baudelaire y Mansilla hacen de la pose una forma de vida : vacían su obra de todo sentido último para abogar por el acto estético en sí mismo. A través de la simulación, logran desintegrar su yo en su producción escrita y en la puesta en escena de sus retratos fotográficos. En este sentido, los escritores se erigen en esnobs victoriosos: se desentienden de las imposiciones de la sociedad para regocijarse en el esteticismo. Su obra no busca un sentido teleológico, sino el puro goce de ser otro.

\section{BIBLIOGRAPHY}

Aira, César, « Mutación narcisista », prólogo a L.V. Mansilla, Esa cabeza toba y otros textos. Buenos Aires : Mate, 2001

Aumont, Jacques, Du visage au cinéma. París : Editions de l'Etoile, 1992.

Barthes, Roland, La cámara lúcida, trad. Joaquim Sala-Sanahuja. Buenos Aires : Paidós, 2011

Baudelaire, Charles, Euvres Complètes, edición de Claude Pichois. París : Gallimard, Bibliothèque de la Pléiade, 1975-1976, 2 vols.

Compagnon, Antoine, Baudelaire. L'irréductible. París : Flammarion, 2014

Contreras, Sandra, « Los tiempos de Lucio V. Mansilla », Cuadernos LIRICO [En línea], 10 | 2014, puesto en línea el 15 marzo 2014, consultado el 04 septiembre 2015. URL : http://

lirico.revues.org/1710; DOI : 10.4000/lirico.1710

Cortés-Rocca, Paola, El tiempo de la máquina. Buenos Aires : Colihue, 2011

Frizot, Michel, Histoire de voir. París : Centre National de la Photographie, 1989.

Goldgel, Víctor, « Entre dandis y rastacueros. Aproximaciones al esnobismo del siglo XIX

latinoamericano ». Mar del Plata : Estudios de Teoría Literaria. Revista digital, Año 3, Nro. 5, 2014, pp. 239-249.

Iglesia, Cristina, La violencia del azar. Buenos Aires : Fondo Cultura Económica, 2003.

Jitrik, Noé, El 80 y su mundo. Buenos Aires : Editorial Jorge Alvarez, 1968. 
De Lusarreta, Pilar, Cinco dandys porteños. Kraft : Buenos Aires, 1943.

Dupuis, Jérôme, «Photographie inédite : un air de Baudelaire », L'express [En línea], , noviembre de 2013, consultado el 15 de marzo de 2014. URL : http://www.lexpress.fr/culture/livre/ photographie-inedite-un-air-de-baudelaire_1301028.html

Lojo, María Rosa, «Los hermanos Mansilla : género, nación, 'barbaries », Abanico [En línea], agosto de 2004. URL : http://www.bn.gov.ar/abanico/A10408/Lojo.htm

Mansilla, Lucio V., Entre-nos. Causeries del jueves. Buenos Aires, Hachette, 1963. Una excursión a los indios ranqueles, Caracas, Biblioteca Ayacucho, 1984.

Molloy, Sylvia, « Imagen de Mansilla », en Ferrari, Gustavo y Gallo, Ezequiel (compiladores), La Argentina del ochenta al centenario. Buenos Aires : Sudamericana, 1980.

Molloy, Sylvia, Poses de fin de siglo. Buenos Aires : Eterna Cadencia, 2012.

Nadar, Félix, Quand j'étais photographe. París : Ernest Flamarion, 1895-1905.

Schvartzman, Julio, Microcrítica. Buenos Aires : Biblos, 1996.

Soulages, François, Estética de la fotografía. Los hijos de Nadar, trad. Víctor Goldstein. Buenos Aires : La Marca, 2005.

Starobinski, Jean, La mélancolie au miroir. Trois lectures de Baudelaire. París : Julliard, 1989.

Viñas, David, Literatura argentina y realidad política. Buenos Aires : Jorge Alvarez Editor, 1964.

Viñas, David, Mansilla entre Rozas y París, en Fondo David Viñas. Buenos Aires : Biblioteca Nacional, 2009.

\section{NOTES}

1. Contreras (2014) se refiere al cliché de la escritura inestable de Mansilla que inaugura Ricardo Rojas en los años 20 con la primera Historia de la literatura argentina y que Viñas logra desmantelar al dedicar casi 40 años de su labor crítica a leer y releer la obra de Mansilla.

2. Pilar de Lusarreta (1943: 160) exclama sobre Mansilla: « [...] ¡y cuánto se retrató!, Dios Mío!»; María Rosa Lojo (2004: 3) señala: «Lucio fue quizá el hombre público argentino con una iconografía más abundante, profusa y con pretensiones artísticas »; Antoine Compagnon (2014: 164) afirma que el número de fotografías que se toma Baudelaire resulta inaudito para los primeros años de la invención.

\section{ABSTRACTS}

According to Víctor Goldgel (2014), the successful snob, that is to say the dandy, questions the ego's integrity. In this way, Charles Baudelaire and Lucio V. Mansilla, as successful snobs, make the simulation a way of living. Mansilla follows Baudelaire $:$ his desire of adopting different egos, 
of pretending to be what he is not. They use writing and photographic reproduction to destroy the unity of the writer's image.

Según Víctor Goldgel (2014), el esnob victorioso, es decir, el dandi, cuestiona la integridad del yo. De esta manera, Charles Baudelaire y Lucio V. Mansilla, en calidad de esnobs victoriosos, hacen de la simulación un modelo de vida. Mansilla sigue a Baudelaire en su deseo de adoptar otros yos, de pasar por lo que no es. Ellos utilizan la escritura y la reproducción fotográfica para destruir la unidad de su imagen de escritor.

Selon Víctor Goldgel (2014), le snob victorieux, c'est-à-dire le dandy, met en doute l'intégrité du moi. Ainsi, Charles Baudelaire et Lucio V. Mansilla, en tant que snobs victorieux, font de la simulation une manière de vivre. Mansilla suit Baudelaire : son besoin d'adopter différents mois, de passer pour ce qu'il n'est pas. Ils utilisent l'écriture et la reproduction photographique pour détruire l'unité de leur image d'écrivain.

INDEX

Keywords: Charles Baudelaire, Lucio V. Mansilla, snob, photography

Palabras claves: Charles Baudelaire, Lucio V. Mansilla, esnob, fotografía

Mots-clés: Charles Baudelaire, Lucio V. Mansilla, snob, photographie

\section{AUTHOR}

MARIANA DE CABO

Universidad Católica Argentina

marianadecabo@gmail.com 